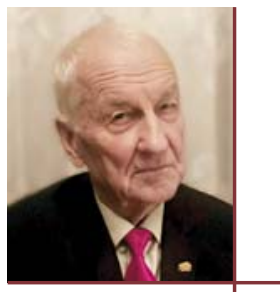

Куприенко П.И.

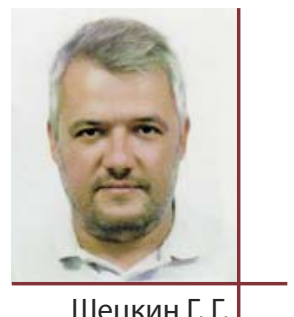

Шецкин Г. Г.

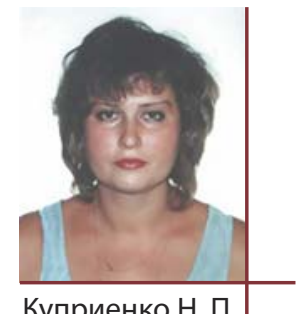

Куприенко Н. П.
Куприенко П. И., д.т.н., профессор,

профессор кафедры ТКД

Киевский национальный университет строительства и архитектуры,

03037, г. Киев, Воздухофлотский пр-т, 31,

$凶$ Tkd362@ukr.net $\approx+38(044)$ 520-01-13

Шецкин Г. Г., ведущий инженер лаборатории физико-химических исследований и строительной керамики,

Государственное предприятие «Научно-исследовательский и проектноконструкторский институт строительных материалов и изделий»,

04080, г. Киев, ул. Константиновская, 68,

$凶$ shetskin@gmail.com $\approx+38(067)$ 404-17-82

Куприенко Н. П., Зав. лаборатории физико-химических исследований и строительной керамики,

Государственное предприятие «Научно-исследовательский и проектноконструкторский институт строительных материалов и изделий», 04080, г. Киев, ул. Константиновская, 68,

凶pkuprienko@ukr.net
Peter Kuprienko, Doctor Technical science, professor,

professor of the department of commodity and commercial activities

Of the Kiev University of Construction and Architecture

Povitroflotsky pr., 31, Kyiv, 03680, Ukraine

$凶$ Tkd362@ukr.net $\$+38(044)$ 520-01-13

Grigory Shetskin, Leading Engineer

of the Laboratory for Physical and Chemical Research

State Enterprise «Research and Design Institute

of Building Materials and Products»

St. Kostantinovskaya, 68, Kiev, 04080, Ukraine

凶shetskin@gmail.com $\approx+38(067)$ 404-17-82

Natalia Kuprienko, head of the laboratory

of Physical and chemical research

State Enterprise «Scientific Research and Desing Institute

of building materials and products»

Kostyantinivska str., 68, Kyiv, 04080, Ukraine

凶k pkuprienko@ukr.net

\title{
СРАВНИТЕЛЬНАЯ ХАРАКТЕРИСТИКА ПРОЦЕССА СТРУКТУРООБРАЗОВАНИЯ, РЕОЛОГИЧЕСКИХ И ТЕХНОЛОГИЧЕСКИХ СВОЙСТВ КОМПОЗИЦИЙ ГЛИН ДЛЯ САНТЕХНИЧЕСКИХ ИЗДЕЛИЙ
}

\author{
ПОРІВНЯЛЬНА ХАРАКТЕРИСТИКА ПРОЦЕСІВ СТРУКТУРОУТВОРЕННЯ, РЕОЛОГІЧНИХ \\ I ТЕХНОЛОГІЧНИХ ВЛАСТИВОСТЕЙ КОМПОЗИЦІЙ ГЛИН ДЛЯ САНТЕХНІЧНИХ ВИРОБІВ
}

\section{COMPARATIVE CHARACTERISTIC OF THE STRUCTURE FORMATION PROCESS, RHEOLOGICAL AND TECHNOLOGICAL PROPERTIES OF CLAY COMPOSITIONS FOR SANITARY PRODUCTS}

Анотация. На основании полученных данных по исследованию реологических свойств составляющих глинистых минералов шликера для фаянсовых изделий установлен механизм структурообразования коллоидно-дисперсных систем на их основе и определены основные пути регулирования технологических свойств. На данном этапе исследований разработан метод регулирования процесса обезвоживания керамического шликера в гипсовой форме в процессе набора черепка.

Ключевые слова: структурообразование, коагуляция, эффективная вязкость, седиментация, суспензия, каолин, дисперсная система, монтмориллонит, шликер.

Анотація. На підставі отриманих даних по дослідженню реологічних властивостей складових глинистих мінералів шлікера для фаянсових виробів встановлено механізм структуроутворення колоїдно-дисперсних систем на їх основі і визначено основні шляхи регулювання технологічних властивостей. На даному етапі досліджень розроблено метод регулювання процесу зневоднення керамічного шлікера в гіпсовій формі в процесі набору черепка. Ключові слова: структуроутворення, коагуляція, ефективна в'язкість, седиментація, суспензія, каолін, дисперсна система, монтморилоніт, шликер. Annotation. On the basis of the obtained data on the study of the rheological properties of the components of clay minerals of the slip for faience products, a mechanism of structure formation of colloid-dispersed systems based on them was established and the main ways of regulating the technological properties were determined. At this stage of research, a method has been developed to regulate the process of dehydrating a ceramic slip in a gypsum form during a set of shards.

Keywords: structure formation, coagulation, effective viscosity, sedimentation, suspension, kaolin, disperse system, montmorillonite, slip.

На рис.1 представлена зависимость вязкости водных суспензий на основе пластичной составляющей различных составов для производства сантехизделий. В качестве ингредиентов были взяты пластичные глины DBX и DBY при соотношении 10:9, ПЛГ-2 и ПЛГ-3 при соотношении 2:1 и композиция Sanblend состоящей из D11, SA12 и D6 соответственно 60:20:20. Для построения зависимости п-Ст использовали значения эффективности вязкости при скорости деформации 5,4 c-1. Измерения проводили на ротационном вискозиметре «Rheotest-2». Вязкость суспензии, помещенной между двумя соосными цилиндрами, определяется по формуле:

\section{$\eta=\left[M\left(R^{2}-r^{2}\right)\right] /\left[4 \pi l\left(w_{H}-w_{B}\right) R^{2} r^{2}\right]$,}

где M-момент, действующий на цилиндр (наружный или внутренний) на определенном отрезке 1 ; $\mathrm{R}$ и $\mathrm{r}$ - радиус наружного и внутреннего цилиндров; $W_{н}-W_{в}-$ их угловые скорости.
Практически при проведении эксперимента на приборе вязкость $\eta$ рассчитывается по формуле $\eta=\tau_{r} / D_{r}$, Па•с, где $\tau_{r}$ - напряжение сдвига, Па; $D_{r}-$ скорость деформации, $\mathrm{c}^{-1}$.

\section{$\tau_{r}=\alpha z$,}

где a - отсчет по шкале прибора; z - табличная величина, которая приведена в инструкции к прибору. Ошибка измерений 3-4\%.

Опытные данные принято представлять в виде кривых: реологической кривой зависимости эффективной вязкости $\eta=f\left(\tau_{r}\right)$, которая отображает зависимость эффективной вязкости п от напряжения сдвига в условиях стационарного, устойчивого и ламинарного течения и реологической кривой течения $D_{\mathrm{r}}=\mathrm{f}\left(\mathrm{gr}_{\mathrm{r}}\right)$, которая отображает зависимость скорости течения Dr от напряжения сдвига. 


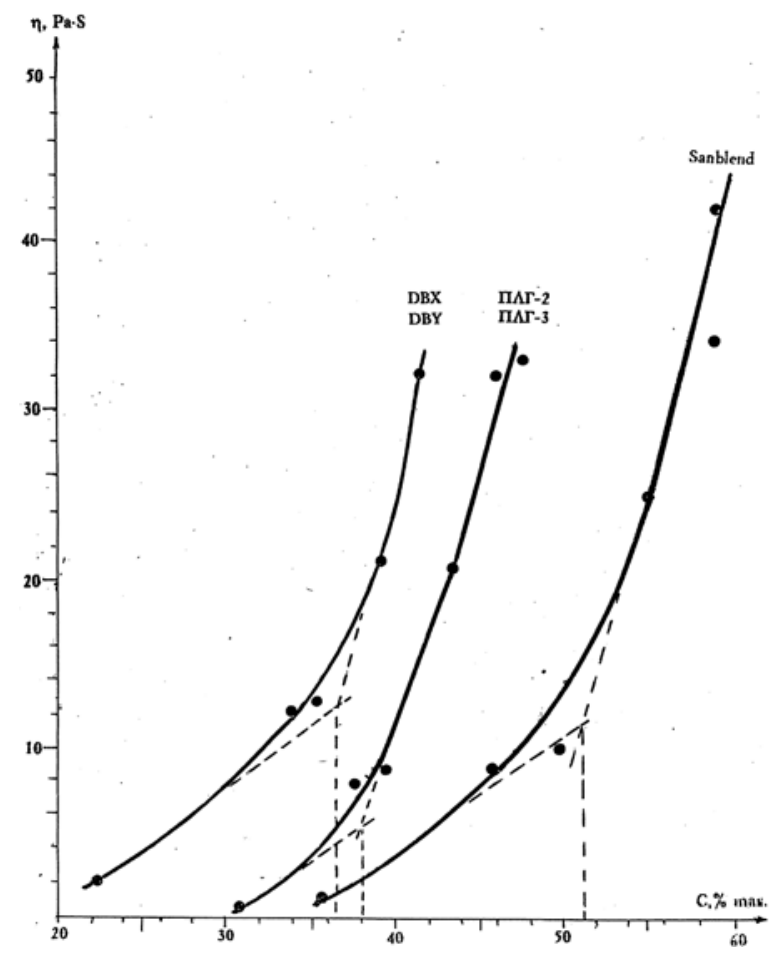

Рис. 1. Зависимость вязкости суспензий пластической составляющей различных составов для сантехизделий от концентрации твердой Измерение вязкости проводилось при скорости деформации $\mathrm{D}_{\mathrm{r}}=5,4 \mathrm{c}^{-1}$.

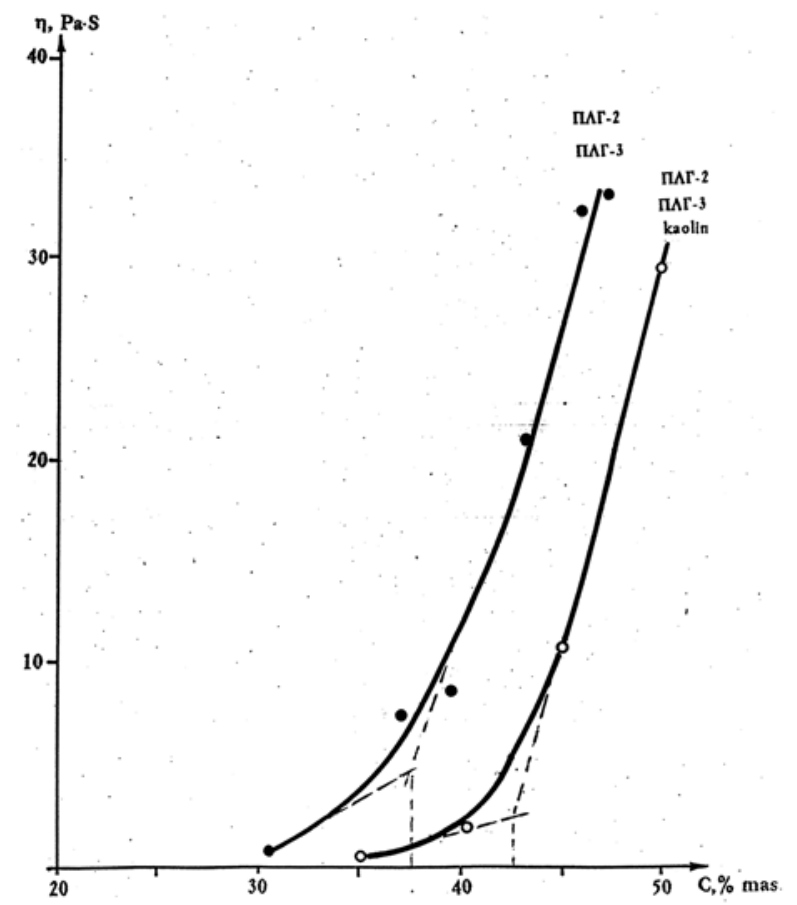

Рис. 2. Зависимость вязкости суспензий при $\mathrm{D}_{\mathrm{r}}=\mathrm{c}^{-1}$ пластичной составляющей (ПЛГ-2 + ПЛГ-3) и пластичной составляющей + каолин заводского состава от концентрации твердой фазы

Общий анализ зависимости $\eta=f\left(C_{T}\right)$ представленной на графике позволяет высказать мнение, что исследуемые дисперсные системы существенно отличаются по структурообразовывающей способности. Наиболее сильно коагуляционное структурообразование проявляется в системе (DBX + DBY) - вода наиболее слабо в суспензиях на основе состава «Sanblend», а суспензия на основе смеси глин ПЛг-2 и ПлГ-3 занимает промежуточное значение. Такой вывод был сделан на основе рассмотрения величин эффективной вязкости изучаемых дисперсных систем от разбавленных до сравнительно высококонцетрированных. На каждой кривой виден ха-

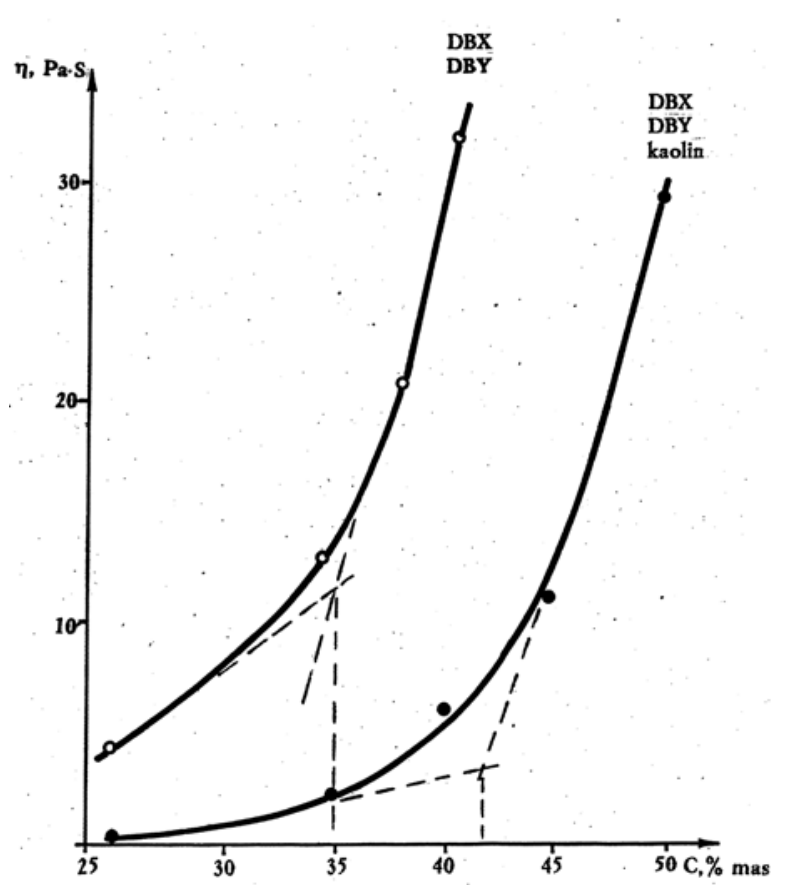

Рис. 3. Зависимость вязкости от концентрации суспензий на основе пластичной составляющей и пластичной составляющей + каолин

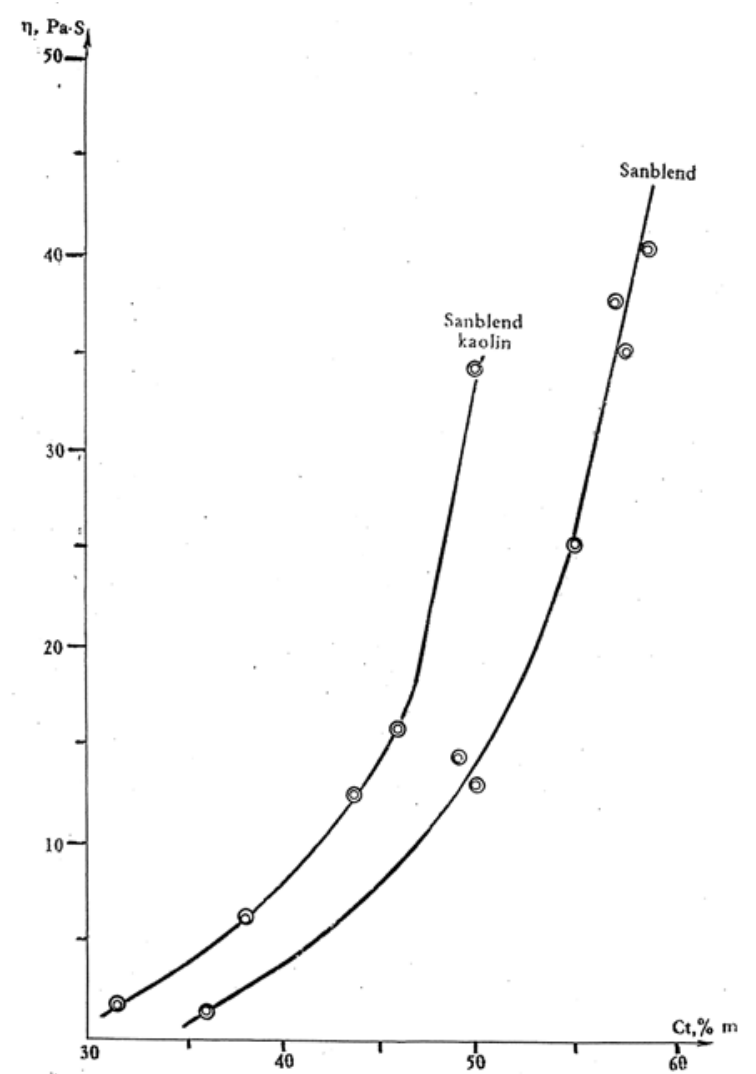

Рис. 4. Зависимость вязкости от концентрации суспензий Sanblend и Sanblend + каолин

рактерный перегиб - рост вязкости после определенной концентрации суспензии. Концентрацию в точке перегиба на кривой $\eta=f\left(C_{T}\right)$ условно принято называть критической концентрацией структурообразования (ККС) $[1,2]$. Суспензия при критической концентрации структурообразования стабильна, не расслаивается, обладает прочностью коагуляционной структуры достаточной для предотвращения седиментации частиц и обеспечения равномерного распределения их в объеме системы. Величина критической концентрации структурообразования - интегральный показатель, зависит от дисперсности частиц твердой фазы, гидрофильно-гидрофобного ба- 
ланса их поверхности, формы частиц, природы дисперсионной среды, присутствия поверхностно-активных веществ и других факторов.

При соблюдении одинаковых условий получения дисперсных систем работа с исследуемыми суспензиями при этой концентрации позволяет выявить влияние тех или иных факторов и сознательно регулировать свойства этих систем с целью оптимизации процесса структурообразования, течения, водоотдачи в технологии производства сантехизделий.

Касательно кривых, представленных на рис.1, надо отметить, что KKC для суспензий пластичной составляющей состава (DBX + DBY) находится в переделах 33\% масс. (ПЛГ-2 и ПЛГ-3) - 38\% масс., а для состава Sanblend - 51\% масс. Уровень вязкости суспензий в области перегиба кривой 6-12 Па'с также характеризует структурообразующую способность изучаемых систем и подтверждает вышесказанную характеристику.

В соответствии с поставленной целью было изучено структурообразование в системах пластичная составляющая - вода по мере увеличения для различных составов. Рассмотрены суспензии, содержащие пластичную составляющую + каолины (рис.2-4).

Для заводских образцов добавка каолина приводит к ослаблению процесса структурообразования, ККС увеличивается приблизительно на 5-7\%, при этом уровень значений $\eta_{э ф}-C_{T}$ смещается в область более низких значений концентрации твердой фазы. ККС для суспензий смеси «Sanblend» с добавкой каолина сдвигается на 5-6\% масс. влево и составляет 43-44\% масс.

На рис. 5-10 представлены зависимости вязкости от напряжения сдвига $\eta-\tau_{r}$ и кривые течения $\mathrm{\tau}-\mathrm{D}_{\mathrm{r}}$ суспензий различной концентрации на основе пластичной составляющей и пластичной составляющей в смеси с каолином. Из большого разнообразия данных, которые можно вычислить из полученных результатов измерений и графического их представления на данном этапе остановимся на общем анализе течения суспензий, численном значении соотношений, которые характеризуют деформационное поведение дисперсных систем. Отношение PK2/PK1 характеризует прочность структуры, образовавшейся в дисперсной системе.

На рис. 5 представлены зависимости вязкость - напряжение сдвига ( $\eta$ - $\tau_{r}$ и напряжение сдвига - скорость деформации (т-Dr) суспензий на основе пластичной составляющей (глины ПЛГ-2 и ПЛГ-3). Анализируя ход реологических кривых можно отметить что с ростом концентрации твердой фазы в суспензии наблюдается усиление процесса структурообразования на что указывает увеличение численного значения отношения $\mathrm{P}_{22} / \mathrm{P}_{11}$ и увеличение области напряжения сдвига, в которой наблюдается снижение эффективной вязкости с выходом на $\eta_{m}$ - вязкость разрушенной структуры. При добавлении каолина в исследуемую суспензию характер реологического поведения суспензии (рис.6) сохраняется тот же, однако уровень прочности структуры для суспензий на основе глин, представляющих пластичную составляющую заводской композиции в смеси с каолином достигается при содержании твердой фазы на 78 \% выше, т.е. добавление каолина заметно снижает процесс структурообразования в системе.

Аналогично рассмотренной выше наблюдается зависимость вязкостных и структурно-механических свойств суспензий глин, применяемых ы технологии сантехизделий на комбинате г. Славянска. при добавлении каолина к пластичной составляющей процесс структурообразования ослабляется: вязкость суспензии снижается, прочностные характеристики также уменьшаются. Это хорошо прослеживается на примере суспензий с одинаковой концентрацией (рис. 7, кр. 2-2I , рис.8, кр. 2-2I ). При одинаковом содержании твердой фазы системы, содержащие каолин, имеют более высокую текучесть и более низкую прочность структуры. Это подтверждается заметным повышением значений соотношения $\eta_{0} / \eta_{m}$ и значениями РК2и РК1.

Реологические параметры суспензий на основе состава «Sanblend» (рис.9,10) при добавлении каолина, наоборот, существенно повышается, при чем, имеет место существенное отличие в характере изменения эффективной вязкости от напряжения сдвига. Область напряжения сдвига, в которой наблюдается переход

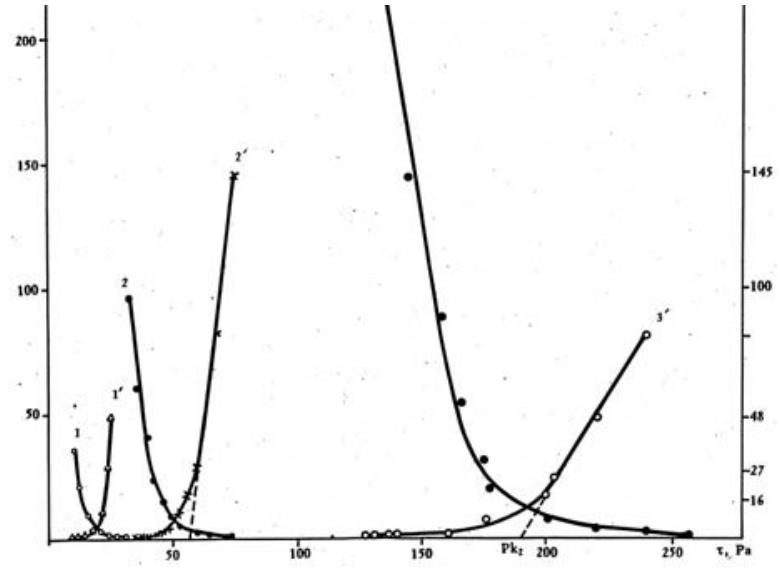

Рис. 5. Реологические кривые зависимости вязкости от на-

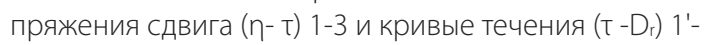

3'суспензий на основе пластичной составляющей заводского состава от концентрации твердой фазы (Ст) 1-30,7; 237; 3-46,3\% масс.

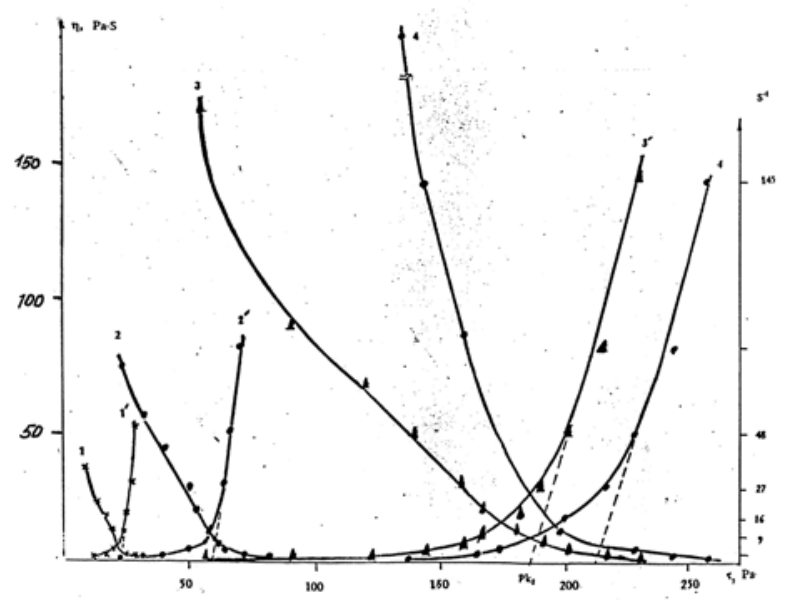

Рис. 6. Зависимость п- т (1-3) и т -Dr (1'-3') суспензий пластичной составляющей + каолин заводского состава от содержания твердой фазы (Ст) 1-40; 2-45; 3-50 \% масс. 44'пластичная составляющая при $C_{т}=46 \%$ масс.

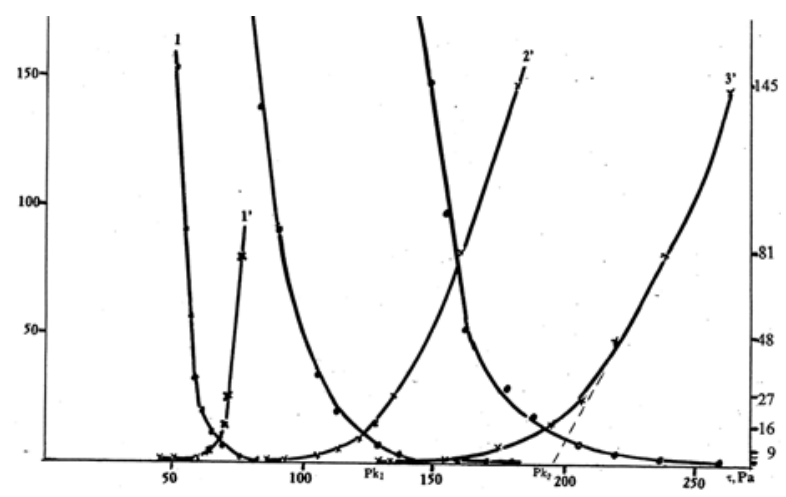

Рис. 7. Зависимость п- т (1-3) и т -Dr (1'-3') суспензий пластичной составляющей от концентрации твердой фазы 
от наибольшей вязкости, практически неразрушенной структуры существенно увеличивается и составляет 100600 Па. Для суспензий глин других составов область напряжения сдвига, в которой наблюдается перепад вязкости $\eta_{\mathrm{o}} \rightarrow \eta_{\mathrm{m}}$ не превышает 250 Па.

Интересные данные получены п определению седиментационного объема осадка. Это простой, надежный метод определения агрегативной устойчивости дисперсного вещества в жидкой среде, позволяющей четко фиксировать изменение агрегативной устойчивости дисперсной системы, вызванной различными факторами: изменение соотношения ингредиентов твердой фазы, рН-среды, наличие поверхностно-активных веществ и других добавок. [3]

Сущность метода заключается в измерении седиментационного объема осадка ( $V_{\text {оc) }}$ из суспензий, содержащих определенное количество твердой фазы за время т.

На рис.11 представлена диаграмма зависимости седиментационного объема осадка для водных суспензий различных глин и глинистых минералов. Полученные данные полностью подтверждают оценку структурообразующей способности рассмотренных систем.

Анализируя полученные данные для состава «Sanblend» можно отметить, что наибольший объем осадка при седиментации глины D11. Композиция «Sanblend» при оседании имеет незначительное повышение объема осадка. Смешивание ингредиентов «Sanblend» с каолином приведет к дальнейшему росту $\mathrm{V}_{\text {ос. }}$

Для других исследуемых систем имеют место свои особенности. Прим смешивании и компонентов пластичной составляющей (ПЛГ-2 иПЛГ-3) объем осадка увеличивается, а при добавлении каолина - уменьшается. Для глин DBX и DBY наблюдается существенное снижение Voc при их совместной седиментации. Добавление каолина приводит к уменьшению осадка.

Изменение седиментационного объема осадка фиксирует изменения происходящие в системе глинистый минерал - вода. Уменьшение $\mathrm{V}_{\text {ос }}$ свидетельствует о стабилизации (повышению агрегативной устойчивости) дисперсного вещества - частицы оседают преимущественно отдельно друг от друга. Повышение объема осадка есть результат агрегации частиц (осадок формируется объемным). Система склонна к коагуляционному структурообразованию, изменению текучести и прочностных характеристик структур, возникающих в данных суспензиях.

Одной из целей этих исследований является сопоставление реологических свойств изучаемых систем с технологическими параметрами, в частности, скорости фильтрации, осуществление регулирования скорости фильтрации с помощью модифицирования поверхности глин с введением специальных добавок.

Литературные данные показывают, что ионообменная способность алюмосиликатов предопределяет целый ряд физико-химических свойств их дисперсий, которые используют на практике. [4-6]

На данном этапе исследований было изучено влияние обменных катионов $\mathrm{Na}$, Са и $\mathrm{Al}$ на прочностные характеристики дисперсных систем и их фильтрующую способность. Влияние обменных катионов оценивали на примере каолинита и монтмориллонита.

Обезвоживание суспензий оценивали по двум методикам.

1. Водопроницаемость по коэффициенту фильтрации. Коэффициентом фильтрации КФ называют количество воды в единицу времени, проходящей через единицу площади поперечного образца при градиенте напора, равным 1. Коэффициент фильтрации имеет раз-

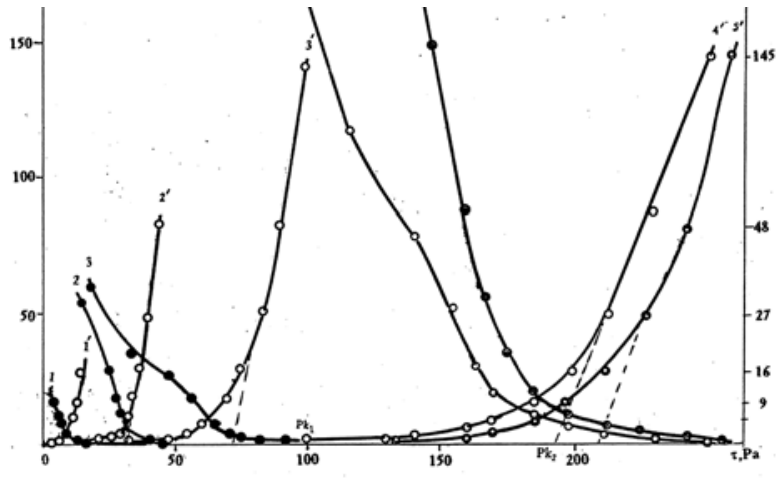

Рис. 8. Зависимость вязкости от напряжения сдвига п- т (14) и кривые течения т - $D_{r}\left(1^{\prime}-4^{\prime}\right)$ суспензий на основе пластичной составляющей + каолин от концентрации твердой фазы: 1-35; 2-40; 4-50\% масс. - суспензия га основе пластичной составляющей при $\mathrm{C}_{\mathrm{r}}=41,2 \%$

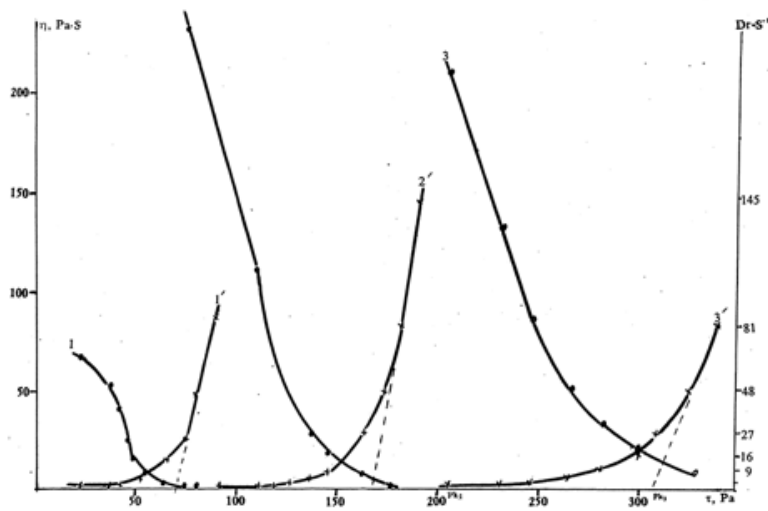

Рис. 9. Зависимость ๆ- т и т - Dr суспензий на основе состава Sanblend от концентрации твердой фазы 1-50; 2-55; 3-59\% мacc.

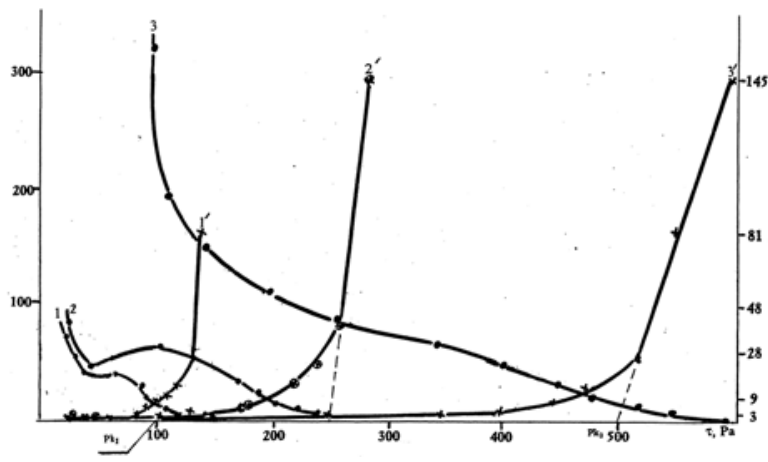

Рис. 10. Зависимость П- т и т -Dг суспензий на основе состава Sanblend + каолин от концентрации твердой фазы 140; 2-50; 3-55\% масс

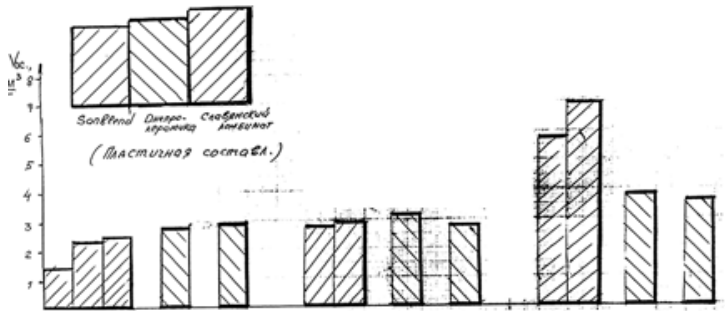

Рис. 11. Объем седиментационного осадка отдельных глин и композиций на их основе 
мерность см ${ }^{3}$ сек/г. Если же выразить потерю напора в единице высоты водяного столба т.е. в см, что общепринято в гидравлике, то $\mathrm{K} \Phi=\mathrm{CM} /$ сек.

2. Водоотдачей (статической) называется количество жидкой фазы, отфильтровавшейся из суспензии через бумажный фильтр под действием избыточного давления в фильтрационной камере при отсутствии движения жидкости вдоль поверхности фильтра. Перепад давления 1 кг/см³ в течении 30 мин. Существует также вакуумный способ определения водоотдачи.

В табл.2 представлены сравнительные данные фильтрационных и прочностных свойств в переходной области влагосодержания систем. Такие резкие отличия водопроницаемости дисперсий катионозамещенных форм монтмориллонита можно объяснить особенностями образования агрегатов частиц, слагающих дисперсную структуру, и соответственно порового пространства, которое образуется при укладке агрегатов. Атом алюминия имеет наивысшую валентность. Адсорбируясь на отрицательно заряженной поверхности монтмориллонита, Al3+ вступает в прочную связь с атомами кислорода или гидроксильными группами кристаллической решетки минерала. Аналогичная связь возможна и между другими соседними частичками, близко расположенными друг к другу. В результате такого взаимодействия происходит сращивание частичек. Т.е. образование сравнительно крупных вторичных агрегатов с узкими внутренними полостями и широкими щелями между агрегатами. Структура химической связи обменного катиона с анионом матричной поверхности монтмориллонита обуславливает образование различных агрегатов, которые формируют дисперсные структуры, резко отличающиеся по водопроницаемости и прочностным показателям (табл. 1).

Значения коэффициентов фильтрации катионзамещенных форм монтмориллонита, соответствующие ранним значениям влагосодержаний исследуемых дисперсных структур (табл. 2) свидетельствует о том, что фильтрационную способность катионзамещенных форм можно изменять в широких пределах, изменяя влагосодержание системы.

Экспериментально показано, что совершенный по кристаллической структуре каолинит с очень низкими значениями емкости обмена образует катионзамещенные формы, которые по фильтрационным и прочностным показателям дисперсных структур мало отличаются и соответствуют ряду:

$\mathrm{Al}$ - форма > $\mathrm{Na}$ - форма > $\mathrm{Ca}$ - форма

Модифицирование поверхности высокодисперсного монтмориллонита катионами $\mathrm{Na}^{+}, \mathrm{Ca}^{2+}, \mathrm{Al}^{3+}$ приводит к образованию дисперсных структур, фильтрационные и реологические показатели которых в значительной мере отличаются, что связано с различной степенью агрегации частиц в зависимости от валентности катиона, фильтрационные и прочностные показатели возрастают при переходе от $\mathrm{Na}$ - формы к Сa - форме и к Al - форме. Коэффициент фильтрации $\mathrm{Al}$ - формы в 20 раз выше, чем для Са-формы и в 145 раз выше, чем для $\mathrm{Na}$ - формы.

В исследуемом диапазоне влагосодержания паст от вязкотекучих до твердообразных коэффициенты фильтрации монтмориллонита изменяются в сотни раз, а каолинита всего лишь 6-7 раз.

В развитии идеи модифицирования поверхности глинистых минералов были изучены модифицированные образцы гидроксильными соединениями Mg и Al. Модифицированию подвергались глинистые составляющие смеси (пластичная составляющая + каолин) различных составов, которые используются в реальных условиях производства.

На рис.12 представлена зависимость вязкости суспензий на основе модифицированных Mg и AІ. Показано, что обработка поверхности глин модификаторами приводит к повышению вязкости, причем более существенно для образцов, модифицированных Al.

Интересные данные (рис.13) получены по определению фильтрации суспензий на основе модифицированных образцов Для суспензий на основе глин, предварительно обработанных модификатором, процесс водоотдачи изменяется, что выражается в изменении времени фильтрации, остаточной влажности обезвоженного образца.

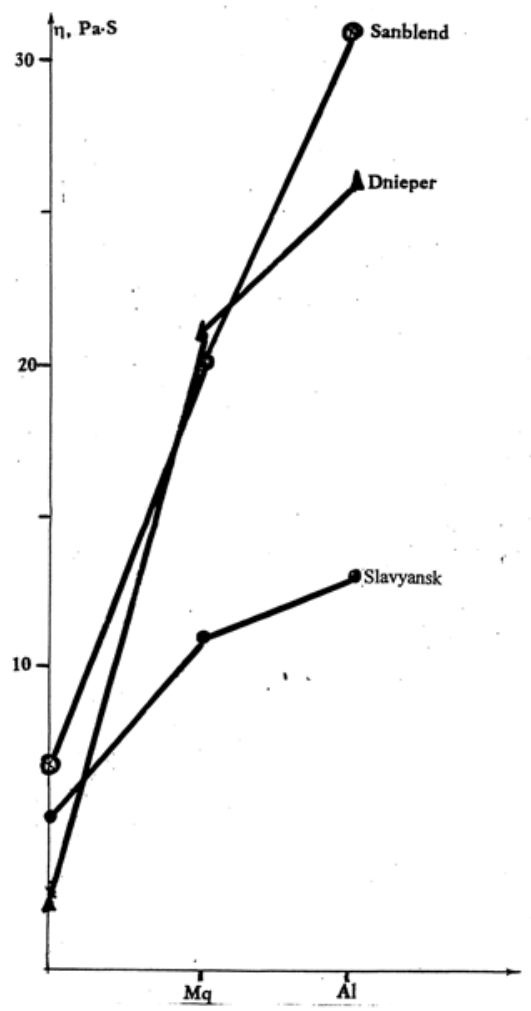

Рис. 12. Вязкость суспензии пластичных составляющих, модифицированных гидроксидами Mg, Al

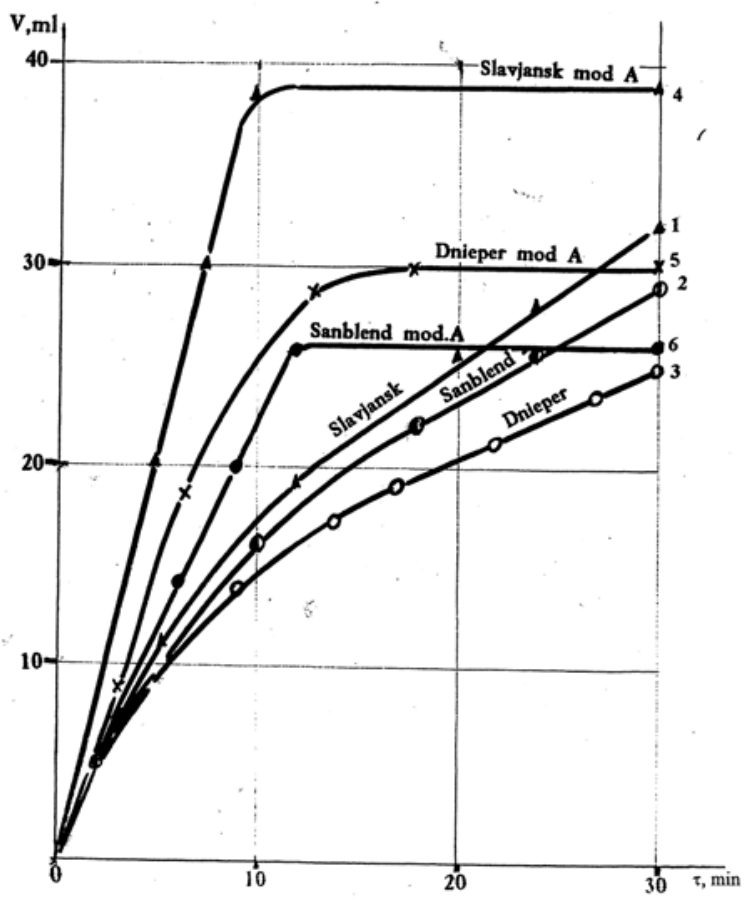

Рис. 13. Фильтрационные свойства суспензий; 1,2,3 - природные глины; 4,5,6 - глины модифицированные 
Водопроницаемость и прочность дисперсных структур катионзамещенных форм слоистых алюмосиликатов

\begin{tabular}{|c|c|c|c|}
\hline Форма минерала & $\begin{array}{c}\text { Коэффициент фильтрации, } \\
\text { К॰ }^{\circ} 10^{+9}, \text { см/сек }\end{array}$ & $\begin{array}{c}\text { Концентрация твердой фазы, } \\
\text { С \% масс. }\end{array}$ & Прочность Ее•104 Па \\
\hline \multicolumn{4}{|c|}{ Каолин } \\
\hline Са - форма & 320,0 & 70 & 29,4 \\
\hline $\mathrm{Na}$ - форма & 400,0 & 68 & 38,3 \\
\hline Al- форма & 500,0 & 67 & 49,0 \\
\hline \multicolumn{4}{|c|}{ Монтмориллонит } \\
\hline $\mathrm{Na- \phi орма}$ & 1,6 & 42 & 18,9 \\
\hline Са- форма & 12,0 & 54 & 63,0 \\
\hline Al- форма & 230,0 & 53 & 104,0 \\
\hline
\end{tabular}

Зависимость водопроницаемости от влагосодержания дисперсных структур

Таблица 2. катионзамещенных форм монтмориллонита

\begin{tabular}{|c|c|c|c|}
\hline \multirow{2}{*}{$\begin{array}{l}\text { Форма } \\
\text { минерала }\end{array}$} & \multirow{2}{*}{$\begin{array}{c}\text { Влажность системы исходная } \\
\text { и конечная, \% }\end{array}$} & \multirow{2}{*}{$\begin{array}{l}\text { Коэффициент фильтрации на- } \\
\text { чальный и конечный см/сек }\end{array}$} & КФ кон. \\
\hline & & & КФ нач. \\
\hline $\mathrm{Na}$ - форма & $49,0-77,6$ & $2,6 \cdot 10^{-10}-4,63 \cdot 10^{-9}$ & 17,8 \\
\hline Са- форма & $27,6-51,9$ & $3,12 \cdot 10^{-9}-1,73 \cdot 10^{-7}$ & 55,4 \\
\hline Al- форма & $37,6-53,5$ & $2,80 \cdot 10^{-9}-9,76 \cdot 10^{-7}$ & 348,0 \\
\hline Природная & $31,0-47,0$ & $2,83 \cdot 10^{-10}-6,0 \cdot 10^{-8}$ & 212,2 \\
\hline
\end{tabular}

На рис.14 представлены сравнительные результаты определения водоотдачи суспензий исходной смеси и смеси модифицированной веществами различной природы. Приведено также значение эффективной вязкости модифицированной системы.

Для образца исходного процесс водоотдачи в течении 30 мин. Не заканчивается, а для образцов модифицированных процесс обезвоживания заканчивается в течении 9-10 мин и 20 мин соответственно. Причем для образца, модифицированного флокулянтом органической природы водоотдача более высокая.

На основании полученных данных по исследованию реологических свойств составляющих глинистых мине-

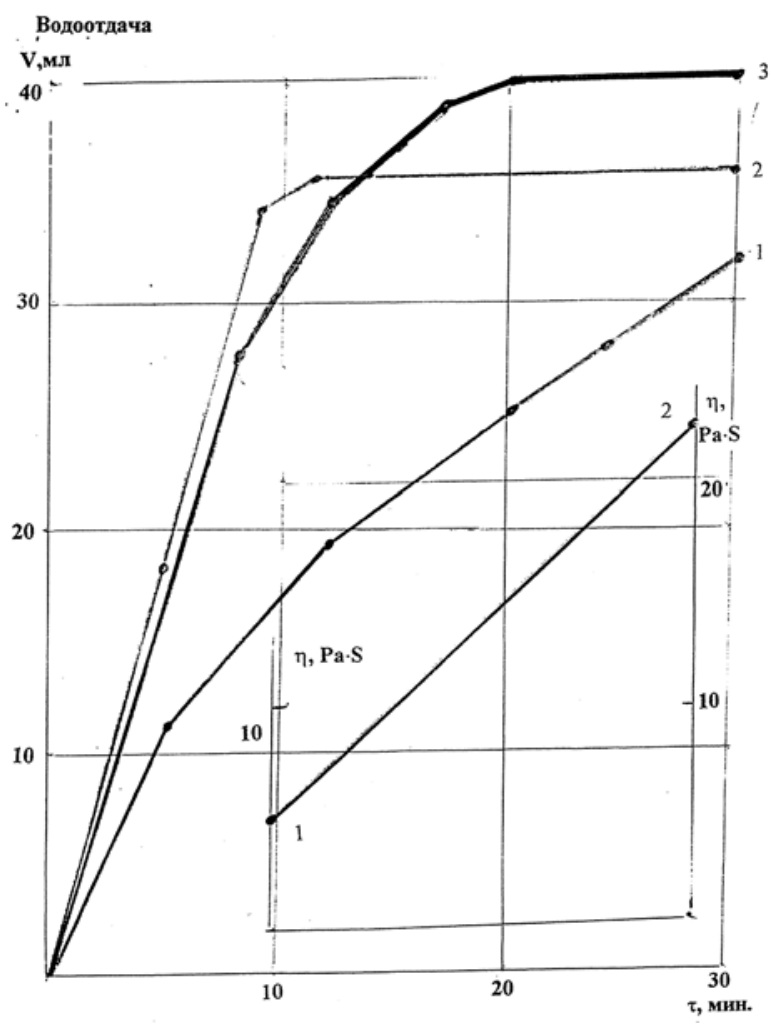

Рис. 14. 1-Водоотдача, вязкость немодифицированного состава шихты для производства сантехизделий; 2-состав модифицированный Al; 3-состав модифицированный добавкой $\mathrm{Al}+$ ПАВ ралов шликера для фаянсовых изделий удалось в значительной мере выяснить механизм структурообразования коллоидно-дисперсных систем на их основе и определить основные пути регулирования технологических свойств. На данном этапе исследований главное внимание было уделено разработке метода регулирования процесса обезвоживания керамического шликера в гипсовой форме в процессе набора черепка.

\section{Выводы}

Разработаны две композиционные добавки комплексного действия, оценено поведение шликера на стадии его получения, влияние на процесс фильтрации, прочность, структуру набранного черепка, его поведение при окончательном обжиге. Лабораторные исследования показали большой потенциал этих добавок для регулирования процесса переработки композиций в технологии получения фаянсовых изделий. Однако следует отметить, что окончательная оценка действия разработанных композиционных добавок будет сделана после проведения промышленных испытаний и определения их действия в реальных условиях производства.

\section{Литература:}

1. Овчаренко Ф.Д., Ничипоренко С.П., Круглицкий Н.Н. Исследования в области физико-химической механики дисперсий глинистых минералов - Киев: Наук. Думка 1965 - 178с.

2. Круглицкий Н.Н. Основы физико-химической механики: в 3-х частях - Киев: Вища школа. 1975-1977.

3. Куприенко П.И. Технические суспензии: регулирование коллоидно-химических и технологических свойств. К. Наук. Думка. 2000-284с.

4. Переверзева И.Н. Исследование свойств дисперсных структур слоистых алюмосиликатов в связи с их водопроницаемостью автореферат дисс. - канд. хим. наук - Киев, 1978-24с.

5. Овчаренко Ф.Д., Круглицкий Н.Н., Русько Ю.А., Мороз И.И., Комская М.С. и др. Каолины Украины Киев, Наук. Думка, 1982 - 367с.

6. Физико-химическая механика и лиофильность дисперсных систем / Под ред. Ф.Д.Овчаренко - К. Наук. Думка 1968-1977. 